\title{
Biogeochemical disruptions across the Cretaceous-Paleogene boundary: insights from sulfur isotopes
}

\author{
ARBIA JOUINI ${ }^{1}$, GUILLAUME PARIS ${ }^{1}$, GUILLAUME \\ CARO $^{1}$, ANNACHIARA BARTOLINI MARIOTTI ${ }^{2}$ AND \\ SILVIA GARDIN ${ }^{2}$ \\ ${ }^{1}$ CRPG-CNRS \\ ${ }^{2}$ CR2P UMR7207-CNRS-MNHN
}

Presenting Author: arbia.jouini@univ-lorraine.fr

The Cretaceous-Paleogene (KPg) mass extinction event 66 million years ago witnessed one of the 'Big Five' mass extinctions of the Phanerozoic. Compositional changes of the ocean-atmosphere system triggered by the impact and/or volcanic massive sulfuric acid inputs likely played a key role in this extinction. Understanding the coeval sulfur biogeochemical cycle may thus help constrain some complex environmental changes that culminated in the KPg mass extinction, including oceanic biogenic carbonate crisis and changes of sea water chemistry and ocean oxygen level.

Here we present the first stratigraphic high resolution isotopic record of carbonate associated sulfate (CAS) based on monospecific planktic and benthic foraminifer samples during the Maastrichtian-Danian transition from IODP pacific site 1209C. Preliminary $\delta^{34} \mathrm{~S}_{\mathrm{CAS}}$ data reveals a major perturbation of the sulfur cycle around the KPg transition with rapid fluctuations (100-200 kyr) of about $2-4 \%$ o $( \pm 0.54 \%, 2 \mathrm{SD})$ during the late Maastrichtian followed by a negative excursion in $\delta^{34} \mathrm{~S}_{\mathrm{CAS}}$ of 2$3 \%$ during the early Paleocene.

An increase in oxygen levels, associated with a decline in organic carbon burial related to a collapse in primary productivity, may have led to the early Paleocene $\delta^{34} \mathrm{~S}_{\mathrm{CAS}}$ negative shift via a significant drop in microbial sulfate reduction. Alternatively, Deccan volcanism could also have impacted the sulfur cycle via direct input of isotopically light sulfur to the ocean. A revised correlation between $\delta^{34} \mathrm{~S}_{\mathrm{CAS}}$ data reported in this study and precise geochronological constraints on the Deccan volcanism phases would allow us to explore this hypothesis. 